\title{
Herbivore Larval Development at Low Springtime Temperatures: The Importance of Short Periods of Heating in the Field
}

\author{
Esther Müller $^{1}$ and Elisabeth Obermaier ${ }^{2}$ \\ ${ }^{1}$ Institute of Ecology and Evolution, University of Bern, Baltzerstrasse 6, 3012 Bern, Switzerland \\ ${ }^{2}$ Department of Animal Ecology and Tropical Biology, University of Würzburg, Am Hubland, 97074 Würzburg, Germany
}

Correspondence should be addressed to Elisabeth Obermaier, o.maier@biozentrum.uni-wuerzburg.de

Received 4 July 2011; Revised 14 October 2011; Accepted 29 October 2011

Academic Editor: Panagiotis Milonas

Copyright ( 92012 E. Müller and E. Obermaier. This is an open access article distributed under the Creative Commons Attribution License, which permits unrestricted use, distribution, and reproduction in any medium, provided the original work is properly cited.

\begin{abstract}
Temperature has been shown to play an important role in the life cycles of insects. Early season feeders in Palaearctic regions profit by the high nutritional quality of their host plants early in the year, but face the problem of having to develop at low average springtime temperatures. This study examines the influence of short periods of heating in the field on larval development and on mortality with the model system Galeruca tanaceti L. (Coleoptera: Chrysomelidae), an early season feeder, that hatches at low springtime temperatures. Field and laboratory experiments under different constant and variable temperature regimes were performed. While in the field, the average daily temperature was close to the lower developmental threshold of the species of $10.9^{\circ} \mathrm{C}$; maximum temperatures of above $30^{\circ} \mathrm{C}$ were sometimes reached. Larvae developed significantly faster, and pupae were heavier, in the field and in an assay with short periods of heating than at the same average temperature under constant conditions in the laboratory. We conclude that larvae profit substantially from short periods of heating and temperature variation in the field and that intervals of high temperature enable insect survival and exploitation of nutrient-rich food resources at early times in the season.
\end{abstract}

\section{Introduction}

With their early arrival in spring, "early season" or "flush" feeders take advantage of the high nutritional quality of their potential food source, itself the result of a high concentration of nitrogen in growing leaves [1]. Many insects prefer young plants or tissues to old ones and are therefore restricted to feeding at certain times of the season [2]. These herbivores may profit by a fast development and high pupal weight due to the readily assimilated nitrogen at this time of the year [3]. On the other hand, at least in Palaearctic regions, herbivores which appear early in the season are vulnerable to low mean and minimum daily temperatures, which might often drop below the lower developmental threshold of the species in question and severely reduce growth and development.

Insects that specialize in using ephemeral resources (e.g., young leaves) should be especially sensitive when the timing of the availability of those resources is unpredictable. Asynchrony with plant phenology and factors that promote it, such as climate change, have a considerable impact on the dynamics of spring-feeding herbivores [4]. Synchronization between bud burst and egg hatch in a Lepidopteran species varies widely with spring temperatures, while an artificial elevation of temperature prolongs the total period of budburst but shortens the period of egg hatching [5].

Climatic parameters in general have been shown to play an important role in insect life. The most important microclimatic parameters are humidity, solar radiation, and wind, as insects essentially heat up by radiation and lose this heat through convection. Insects, and especially their larvae, are highly sensitive to these variables because of their small size and their relatively large surface area [6]. Temperature plays a major role within the abiotic factors, representing one of the most important environmental factors in the life cycle of insects. In particular, it has been shown to have a considerable influence on their development [7-9]. In general, there is an optimal temperature for the development of a species within a favoured range, where mortality is especially low and development time short. A number of adverse physiological reactions can occur when development takes place 
at temperatures below this optimum. The chemical reactions of the endocrine system slow down with the cold [10], and growth rate is reduced. Some insects step into a diapause to escape low temperatures [11]. Cold temperatures are also able to change the correlation between body size and the beginning of metamorphosis. Larvae that mature at lower temperatures often produce under- or oversized adults [10].

Below a certain threshold, many insects come to a developmental arrest, but can survive. The temperature at which growth stops is referred to as the "lower developmental threshold." It is specific to each species and is known precisely for only a few. For the wax moth Galleria mellonella Linnaeus, for example, the lower developmental threshold is $19^{\circ} \mathrm{C}$, while for the Lepidopteran Xestia C-nigrum Linnaeus, it is only $5^{\circ} \mathrm{C}[10]$ - despite their distribution area being very similar. As with growth rate, development time is also related to temperature. Typically, development time decreases exponentially with increasing temperature [12-14].

The influence of temperature upon insect development is related not only to the daily mean average, but also to the rate of temperature change. Likewise, growth is expected to be related to both duration and quantum of temperature above thresholds. Insects have frequently been shown to develop more rapidly, lay more eggs, suffer a lower mortality, or complete their life cycle within a wider temperature range when temperatures are fluctuating, like they predominate in the field, than at constant temperatures, as long as the maximum and minimum of the fluctuating temperature are within the optimal range of development for the organism [15-17]. While the effects of fluctuating versus constant temperatures have already been well studied, little is currently known about the effects of short periods of heating for larval development and for the growth of Palaearctic insect species in the field. This might be achieved for larvae and adults through, for example, their basking behaviour [18], but Richards and Suanraksa [19] have also shown that energy reserves for embryonic development were sufficient for considerable periods spent below the constant temperature threshold, provided that enough time was spent at much higher temperatures beforehand.

The polyphagous leaf beetle Galeruca tanaceti Linnaeus was used as the model organism for studying the influence of short periods of heating and temperature variations in the field on the larval development of an early season feeder. The adult females deposit their egg clutches with the beginning of the fall in herbaceous vegetation, preferentially on high and dry blades of grass. While the adult beetles die, the eggs are the overwintering form. Between March and April, at cold springtime temperatures, the larvae emerge and develop while feeding on the first young leaves of their host plants [3]. After approximately four weeks of feeding, the larvae pupate after the fourth larval stage, in the soil.

In this study, we examine the influence of short periods of heating and of temperature variation in the field on herbivore larval development. An adaptation to low temperatures close to the lower developmental threshold is discussed as a prerequisite for early season feeders in Palaearctic regions, so that they are able to exploit the high nutritional quality of their food resource at this time of the year. Larval development was studied under field conditions, and under different temperature regimes in the laboratory, to calculate the lower developmental threshold of the species and to help evaluate the field data.

\section{Material and Methods}

2.1. Study System. The field experiment was performed on dry grassland in the Hohe Wann Nature Reserve in Lower Frankonia (Northern Bavaria, Germany, $50^{\circ} 03^{\prime} \mathrm{N}, 10^{\circ} 35^{\prime} \mathrm{E}$ ). The study site was grazed by sheep until a few years ago. In the two years prior to the study, the site was no longer managed. Randomly picked plots were chosen with the help of GIS and GPS.

The tansy leaf beetle, Galeruca tanaceti, is polyphagous and feeds on species of the families Asteraceae, Brassicaceae, Caryophyllaceae, Dipsacaceae, Liliaceae, Lamiaceae, Polygonaceae, and Solanaceae [3]. In the study area, one of the main host plants of G. tanaceti is yarrow, Achillea millefolium L. (Asterales: Asteraceae) [20], but larvae can also be found feeding on Centaurea jacea L. (Asterales: Asteraceae) and Salvia pratensis L. (Lamiales: Lamiaceae).

In fall, females of the tansy leaf beetle deposit their egg clutches on vertical structures within the herbaceous vegetation layer, where the egg clutches then hibernate [21]. After hatching in March-April, the larvae seek suitable host plants close to the oviposition site, on which they feed for about four weeks until pupation [3]. After pupation, the adults can be found from early June onwards before they enter reproductive diapause in midsummer.

2.2. Larval Development and Mortality. Prior to the experiments, in fall, egg clutches of $G$. tanaceti were collected from different sites of the reserve and stored over the winter in a closed cage under natural climatic conditions. In spring, egg clutches were transferred to the laboratory and kept at room temperature until hatching of the larvae. Egg clutches were checked daily for hatching larvae. In the field as well as in the climate chambers, the development time of larvae from eclosion to pupation, pupal weight, and mortality rate were all registered. Only larvae that hatched within $24 \mathrm{~h}$ of the start of the experiment were used. The larvae of the different egg clutches were mixed prior to use, to ensure a random assignment to treatments.

\subsection{Experimental Setup}

2.3.1. Field Experiments. After transfer to the field, larvae developed on a dry grassland site in the Hohe Wann Nature Reserve in 40 completely closed gauze cages with a size of $40 \times 40 \mathrm{~cm}$. The cages consisted of a wooden frame covered with gauze mesh on all sides, including the top. The mesh width of the gauze was $1.2 \mathrm{~mm}$ because of the very small size of the newly hatched larvae. It is possible the gauze may have shaded the larvae and reduced $T$ max; however, the negative effects of closed cages on larval development in comparison to treatments with open cages could not be observed [Müller, unpublished data]. To avoid the escape of the larvae, the cages were placed flush with the soil. 
Additionally, the bottom rim was sealed with soil. All cages included the same number of plants of the main host plant of the beetle, Achillea millefolium L.. 10 larvae, hatched within 24 hours of the start of the experiment, were positioned on the same host plant in the centre of each cage. The larvae were placed together in groups of 10 larvae per cage to simulate natural conditions as closely as possible, for usually multiple larvae hatch out of the egg clutch at the same time. After 28 days, at the end of the feeding phase, the remaining larvae were counted, collected, kept singly in boxes under natural conditions, and provided with food until pupation. All pupae were weighed immediately after pupation. The experiment was repeated once (1st cycle: 4/22-5/19 and 2nd cycle: 5/19-6/15). Additionally the air temperature was recorded during both cycles of the experiment. For this, a thermobutton (Dallas Semiconductor "DS 1921L-F5X Thermochron iButton") was installed in each cage at a $30 \mathrm{~cm}$ height (mean height of egg clutches) and shaded. The temperature was recorded once every hour during both experimental periods.

2.3.2. Laboratory Experiments. Laboratory treatment groups were installed as follows: constant temperatures at $15^{\circ} \mathrm{C}$ (1) and $23^{\circ} \mathrm{C}(2)$, variable temperature with short periods of heating at a temperature of $18^{\circ} \mathrm{C}$ for 22.5 hours, and at $28^{\circ} \mathrm{C}$ for 1.5 hours (daily mean: $18.6^{\circ} \mathrm{C}$ ) (3). All three climatic chambers received the same daylight conditions, according to the conditions in the field (L/D: 14/10 hours). The experiment began when the larvae, which had hatched within less than 24 hours, were exposed to a certain temperature according to their treatment group. The larvae were kept singly in plastic boxes to exclude interaction influences and were fed with their main host plant, Achillea millefolium ad libitum. 17 larvae were kept in each climatic chamber.

\subsubsection{Calculation of Lower Developmental Threshold and} Degree Days. In this study, for the calculation and graphical definition of the lower developmental threshold, developmental data from two constant temperatures were used $\left(15^{\circ} \mathrm{C}\right.$ and $\left.23^{\circ} \mathrm{C}\right)$, after the line-fitting method of Ikemoto and Takai [22]. A linear regression was calculated of the rate of development (1/D) for the larvae of both chambers and related to the linear degree-day model (e.g., $[23,24])$. This is based on the assumption that the rate of development (1/D) increases linearly with incubation temperature $T$ in the range of temperatures usually experienced. The lower developmental threshold results in the intersection of the regression line with the $x$-axes.

In poikilothermic organisms, it is assumed that the developmental rate depends on temperature in such a way that the product of the duration of development $D$ (days) and the incubation temperature $T$ (degrees) above the speciesspecific lower developmental threshold $t_{0}$ is represented by a constant $k$ (degree days). Thus, a specific number of degree days, the so-called "thermal constant $k$ " (measured in degree days $[\mathrm{DD}]$ ), are required for an individual to complete development (e.g., $[25,26])$. For identification of the development time, the duration in degree days was calculated along with the duration in calendar days for all larvae investigated (field and laboratory).

Degree days are a measuring unit for the amount of heat that acts on animals or plants above a specific developmental threshold temperature. This amount is counted over a period of 24 hours. One degree day is counted for every degree over the specific developmental threshold (lower developmental threshold). Thus, multiple degree days can be accumulated over a period of 24 hours [26]. Different kinds of calculations are possible. If the minimal temperature does not drop below the lower developmental threshold, the so-called "average method" is used (1). This method was used for the climate chamber data.

$$
\begin{aligned}
\mathrm{DD}= & {\left[\frac{(\text { maximal temperature }+ \text { minimal temperature })}{2}\right] } \\
& - \text { base temperature. }
\end{aligned}
$$

If the minimal temperature drops below the lower developmental threshold, the "modified sine wave method" is used. This method takes advantage of the fact that daily temperatures behave similarly to sine functions. The sum of degree days is calculated via the areas under the sine waves. A reference table is available for ease of use, where the degree days can be read off for precise minimal temperatures [26]. The "sine wave method" was used for calculation of the degree days of the field experiment, because the temperatures fluctuated and dropped below the base temperature. For calculation purposes, the maximum and minimum temperature of each cage on each day was noted. Afterwards, the average maximum and the average minimum temperature across all cages were calculated, separately for each run. With these averages, the number of degree days was taken from the reference table for each day.

2.3.4. Statistical Analysis. The calculation of the degree days was performed after Herms [26]. Treatment groups of larval weight, development time, and mortality were compared by a GLM after testing for normal distribution. All statistical analyses were performed with Excel 2003 or SPSS 14 for Microsoft Windows.

\section{Results}

3.1. Laboratory Experiment. The climate chamber experiment showed a significant difference in the development time of the larvae over all treatment groups $(F=1911.806$; $P<0.001 ; n_{1}=5 ; n_{2}=13 ; n_{3}=14$ ) (Table 1). Mean development time of larvae differed between 24 days (constant temperature group: $23^{\circ} \mathrm{C}$ ) and more than 52 days (constant temperature group: $15^{\circ} \mathrm{C}$ ). In the treatment with variable temperatures and a short period of heating $\left(18^{\circ} \mathrm{C} / 28^{\circ} \mathrm{C}\right.$; mean daily temperature: $18.6^{\circ} \mathrm{C}$ ) and a mean development time of 32 days until pupation, development was already strongly accelerated when compared to the $15^{\circ} \mathrm{C}$ group with constant temperatures.

Likewise, the weights of the pupae differed significantly between the treatment groups $\left(F=52.483 ; P<0.001 ; n_{1}=\right.$ $\left.5 ; n_{2}=13 ; n_{3}=14\right)$. The pupae of the $15^{\circ} \mathrm{C}$ treatment group 
TABle 1: Comparison of larval development of the different treatment groups in the climate chambers and in the field with a statistics column, showing the differences between all groups. Different letters indicate significant differences between treatment groups, shown with development time, weight, and mortality.

\begin{tabular}{|c|c|c|c|c|c|c|}
\hline \multirow{2}{*}{ Treatment group } & \multicolumn{3}{|c|}{ Climate chamber } & \multicolumn{2}{|c|}{ Field } & \multirow{2}{*}{ Statistics } \\
\hline & $18^{\circ} \mathrm{C} / 28^{\circ} \mathrm{C}$ & $23^{\circ} \mathrm{C}$ & $15^{\circ} \mathrm{C}$ & (1) run $\left(15.0^{\circ} \mathrm{C} \pm 0.3\right)$ & (2) run $\left(13.0^{\circ} \mathrm{C} \pm 0.2\right)$ & \\
\hline $\begin{array}{l}\text { Development time [days] } \\
(\mathrm{x} \pm \mathrm{SD})\end{array}$ & $32.00 \pm 1.03^{\mathrm{a}}$ & $24.00 \pm 0.75^{\mathrm{b}}$ & $52.00 \pm 0.89^{c}$ & $31.00 \pm 0.0^{\mathrm{a}}$ & $31.00 \pm 0.00^{\mathrm{a}}$ & $\begin{array}{c}F=1063.43 \\
P<0.001\end{array}$ \\
\hline $\begin{array}{l}\text { Physiological development } \\
\text { time [degree days] }\end{array}$ & 265.64 & 290.40 & 221.40 & 293.00 & 200.00 & \\
\hline Pupal weight $[\mathrm{mg}](\mathrm{x} \pm \mathrm{SD})$ & $42.00 \pm 5.51^{\mathrm{a}}$ & $49.00 \pm 3.76^{\mathrm{a}}$ & $18.00 \pm 1.95^{\mathrm{a}}$ & $41.00 \pm 14.76^{\mathrm{a}}$ & $39.00 \pm 16.55^{\mathrm{a}}$ & $\begin{array}{c}F=17.985 \\
P<0.001\end{array}$ \\
\hline Mortality [\%] & $18^{\mathrm{a}}$ & $23^{\mathrm{a}}$ & $70^{\mathrm{b}}$ & $90^{\mathrm{b}}$ & $90^{\mathrm{b}}$ & $\begin{array}{c}F=36.442 \\
P<0.001\end{array}$ \\
\hline
\end{tabular}

were significantly lighter than those of the other treatment groups in spite of their long development time (Table 1). Regarding pupal weight, the pupae of the treatment group with variable temperatures and a short period of heating in the climatic chamber were heavier than those in the constant $15^{\circ} \mathrm{C}$ group.

Among the laboratory treatment groups, mortality of the $15^{\circ} \mathrm{C}$ treatment was highest $(>70 \%)$ and differed significantly from the mortality of the larvae of the two other groups $(F=6.204 ; P=0.001 ; n=17)$. At $15^{\circ} \mathrm{C}, 12$ larvae died, at $23^{\circ} \mathrm{C}, 4$ larvae died, and at $18^{\circ} \mathrm{C} / 28^{\circ} \mathrm{C}, 3$ larvae did (Table 1). Based on the developmental data of the two chambers with constant temperatures $\left(15^{\circ} \mathrm{C}\right.$ and $\left.23^{\circ} \mathrm{C}\right)$, and an extrapolation after the line-fitting method [22], a "lower developmental threshold" of $T_{0}=10.9^{\circ} \mathrm{C}$ was calculated for the development of Galeruca tanaceti.

3.2. Field Experiment. In the field experiment, the mean daily temperature differed between the two cycles of the experiment where larvae were exposed. The mean daily temperature of the first cycle $\left(15^{\circ} \mathrm{C} \pm 0,33\right)(4 / 22-5 / 19)$ was higher than that of the second cycle $\left(13^{\circ} \mathrm{C} \pm 0.2\right)(5 / 19-$ $6 / 15$ ) (Figure 1). Maximum daily temperatures varied from $15^{\circ} \mathrm{C}$ to $33^{\circ} \mathrm{C}$ in the first cycle and from $13^{\circ} \mathrm{C}$ to $32^{\circ} \mathrm{C}$ in the second cycle, reaching $30^{\circ} \mathrm{C}$ and above during several days in each experimental cycle. Regarding the degree days, the first cycle contained more degree days and got a higher physiological development time of $k_{1}=293^{\circ} \mathrm{d}$ compared to fewer degree days and lower physiological development time $\left(k_{2}=200^{\circ} \mathrm{d}\right)$ in the second cycle, caused by lower minimum daily temperatures and more days with a lower mean temperature (Figure 1, Table 1). Nevertheless, all larvae of both groups took 31 days for development. The mean pupal weight was $41 \mathrm{mg} \pm 14.76(n=400)$ in the first cycle and $39 \mathrm{mg} \pm 16.55(n=400)$ in the second one. The rate of mortality was very high, and $90 \%$ of the larvae in both cycles died or disappeared.

\section{Discussion}

This study investigates how larvae of an early season feeder, the leaf beetle $G$. tanaceti, manage to develop at relatively low

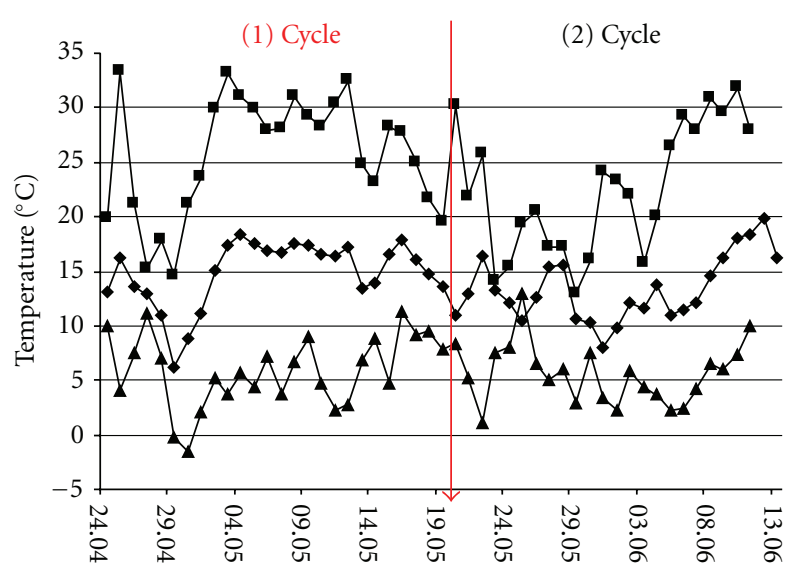

Figure 1: Temperature gradation for both cycles of the field experiment with mean $(\boldsymbol{\vee})$, maximum $(\boldsymbol{\square})$, and minimum $(\boldsymbol{\Delta})$ mean daily temperatures measured at $0.3 \mathrm{~m}$ height $(n=40)$.

springtime temperatures and profit at the same time by the high nutritional quality of their host plants at that time of the year.

Field and laboratory experiments under different temperature regimes were performed. Mean daily temperatures in the field turned out to exceed the lower developmental threshold of the species $\left(10.9^{\circ} \mathrm{C}\right)$ by only a few degrees Celsius. The lower developmental threshold can vary between different Coleopteran species. The Curculionidae species Cionus latefasciatus Voss, for example, has a threshold temperature of $7.7^{\circ} \mathrm{C}$ [27], whereas for the lower developmental threshold of G. tanaceti-larvae, a temperature of $10.9^{\circ} \mathrm{C}$ was determined according to the developmental data of the two chambers with constant temperatures $\left(15^{\circ} \mathrm{C}\right.$ and $\left.23^{\circ} \mathrm{C}\right)$ and an extrapolation after the line-fitting method [22]. Mean daily temperatures during both cycles of the field experiment ((1) cycle: $15^{\circ} \mathrm{C} \pm 0.33$; (2) cycle: $13^{\circ} \mathrm{C} \pm 0.20$ ) therefore exceeded, by two to four degrees on average, the lower developmental threshold of the species, at which no growth or development occurs. Minimum daily temperatures were almost always below the lower developmental threshold, sometimes even dropping to zero degrees Celsius. In general, 
low temperatures can affect development negatively by causing low pupal weight and prolonged development time and thereby reducing fitness via predation pressure [28], disadvantages in mating [29-31] or fewer and smaller offspring [32].

Mean daily temperatures in the field were therefore either lower than or equal to the constant $15^{\circ} \mathrm{C}$ climatic chamber. In spite of this, larval development in the field, provided with short periods of heating, differed significantly from that of the larvae in the constant $15^{\circ} \mathrm{C}$ climatic chamber. Larvae in the field showed an almost twice as fast development and were more than twice as heavy as in the constant $15^{\circ} \mathrm{C}$ climatic chamber. We assume that larval development at very low temperatures, even if partly below the lower developmental threshold, is possible if there are heating periods with higher temperatures in between and which can be taken advantage of by the larvae. Maximum daily temperatures in the field varied between $15^{\circ} \mathrm{C}$ and $33^{\circ} \mathrm{C}$, reaching values of $30^{\circ} \mathrm{C}$ and above during several days in each experimental cycle. The use of short periods of high temperature and the regulation of body temperature to maximise radiative gain can be achieved, for example, by basking behaviour $[6$, $19,33]$. Insects are often found basking on leaves where temperatures are reached that are several degrees higher than the surrounding air, caused by reflected radiation, longwave radiation reradiated from the warm leaf, and possibly convection and heat conducted from the warm leaf [19]. Obviously, basking is especially important during colder weather periods. For adult $G$. tanaceti-beetles, surface temperature was on average $4^{\circ} \mathrm{C}$ higher while basking in the sun as compared to that of the plant surface on which they were resting (Tearasa, pers. communication).

Beside exposure to short periods of heating, temperature variation in comparison with constant temperatures can also help explain the more rapid development of insects at the same mean daily temperatures [17]. Blanckenhorn [11] has described, using the yellow dung fly, how development time is shorter at variable temperatures in the field than with the same mean constant temperature. The same was found by Sehnal [10] in the context of development at low temperatures. This phenomenon, therefore, seems to be fairly widespread among insects; its underlying mechanisms, however, remain poorly understood. With the field and laboratory data available in this study, it is difficult to discriminate between the two mechanisms. T max, however, seems to be a very important factor for larval development at relatively cold average springtime temperatures, as indicated by the climatic data from the field and larval development in the $18 / 28^{\circ} \mathrm{C}$ chamber.

The $18 / 28^{\circ} \mathrm{C}$ chamber, with a relatively low mean daily temperature $\left(18.6^{\circ} \mathrm{C}\right)$, shows that a short time spent heating per day (in the case of the $18 / 28^{\circ} \mathrm{C}$ chamber, $1.5 \mathrm{~h}$ per day) seems to be sufficient to accelerate larval development and change developmental parameters, such as development time and pupal weight, to values comparable to those in the field. Mortality is much lower than in the field, probably because of the constant conditions in the climatic chamber and the absence of natural enemies or adverse abiotic factors such as rain and wind. The short period of heating per day in the climatic chamber might be equivalent to heating by sunshine or the higher temperatures over midday in the field (Figure 1). In the field, however, larvae may also regulate body temperature independently from ambient temperatures by basking, and this hinders the comparison of field with lab work.

The larvae of the constantly heated $23^{\circ} \mathrm{C}$ chamber showed, in spite of this, the shortest development time, with 24 days on average and the highest pupal weight compared to the $15^{\circ} \mathrm{C}$ chamber. This temperature might resemble one close to the temperature optimum of the species. Furthermore, this optimal development demonstrates that the prolonged larval development and high mortality in the $15^{\circ} \mathrm{C}$ chamber were not due to insufficient conditions in the laboratory, but rather that the chosen temperature regime and progression was responsible for the values obtained. A comparison of the two constant chambers of $15^{\circ} \mathrm{C}$ and $23^{\circ} \mathrm{C}$ shows, additionally, that with the chosen temperature regimes, there was neither a positive correlation between body size and development time (calendar days) — as is commonly described in life history theory-nor was there a negative correlation of body size and development time (expressed as degree days), as found by Blanckenhorn [11]. This might be due to extremely unfavourable conditions at constant $15^{\circ} \mathrm{C}$ which could not be completely compensated for by a longer time of development. In any case, surviving pupae stayed rather small at this low temperature.

The findings of Ratte [12] suggest yet another explanation for the better results of the field study in comparison to the results of the constant $15^{\circ} \mathrm{C}$ treatment group in the laboratory. He concluded that some insects grow faster if they are also exposed to temperatures below their lower developmental threshold. The larvae of $G$. tanaceti were exposed to temperatures below their lower developmental threshold $T_{0}$ in the field, but not in the constantly heated $15^{\circ} \mathrm{C}$ chamber. The differing development times of 52 days in the climate chamber and only 31 days in the field might also be partly explained by this observation.

The identical development time of all larvae of both field runs is of considerable interest. One explanation could be that the transport from the field to the laboratory after the larvae stopped feeding represented some kind of signal for pupation. Pupation may have been induced by a temperature change, the handling itself, or some alteration of other microclimatic factors.

G. tanaceti is well adapted to its early appearance in March/April at low springtime temperatures. Larvae are black in colour and so absorb the sunlight and use it for movement, feeding, and metabolism. It has been shown that, at least in some instances, specimens from the warmer parts of the range are generally brighter and paler than those from the same taxon collected in cooler areas [6]. Furthermore, overwintering in the egg stage enables larval development at precisely the time of the first bud burst, when the quality of the food resource is especially high. Additionally, these "early season feeders" have only a few feeding competitors at the time of their major growth and development. Finally, the reduced development larvae, suffering from low temperatures close to or below the lower 
developmental threshold, can be compensated for by short periods of heating or temperature variation. They enable the larvae to develop at almost normal speed even at early springtime conditions in the field. Disadvantages, such as a possible (and possibly worsening) lack of synchronization of hatching with the availability of the host plants due to climate change $[4,5]$, and slow development at temperatures close to the lower developmental threshold, are at least partly compensated for in the aforementioned ways. As long as the extreme values of thermal conditions are not too high to induce stress in the organisms [34], short periods of heating in the first place enable the exploitation of nutrient-rich food resources at this time of the year.

\section{Acknowledgments}

The authors thank H.-J. Poethke for encouraging and hosting this study at the ecological field station Fabrikschleichach, two anonymous reviewers for their valuable comments, and the Council of Lower Frankonia for permission to work in the nature reserve Hohe Wann.

\section{References}

[1] T. C. R. White, The Inadequate Environment, Springer, Berlin, Germany, 1993.

[2] S. Y. Strauss and A. R. Zangerl, "Plant-insect interactions in terrestrial ecosystems," in Plant-Animal Interactions. An Evolutionary Approach, C. M. Herrera and O. Pellmyr, Eds., pp. 77-106, Blackwell Science, Oxford, UK, 2002.

[3] E. Obermaier and H. Zwölfer, "Plant quality or quantity? Host exploitation strategies in three Chrysomelidae species associated with Asteraceae host plants," Entomologia Experimentalis et Applicata, vol. 92, no. 2, pp. 165-177, 1999.

[4] R. E. Forkner, R. J. Marquis, J. T. Lill, and J. L. Corff, “Timing is everything? Phenological synchrony and population variability in leaf-chewing herbivores of Quercus," Ecological Entomology, vol. 33, no. 2, pp. 276-285, 2008.

[5] H. H. de Vries, S. H. Ens, G. de Graaf et al., "Synchronization of egg hatching of brown hairstreak (Thekla betulae) and budburst of blackthorn (Prunus spinosa) in a warmer future," Journal of Insect Conservation, vol. 15, pp. 311-319, 2011.

[6] P. G. Willmer, "Microclimate and the environmental physiology of insects," in Advances in Insect Physiology, pp. 1-57, Academic Press, London, UK, 1981.

[7] R. Eckert, D. Randall, W. Burggren, and K. French, Tierphysiologie, Thieme, Stuttgart, Germany, 2002.

[8] S. C. Stearns, The Evolution of Life-Histories. Natural Temperature Variation Affects Larval Survival, Development and Hsp70 Expression in a Leaf Beetle, Oxford University Press, New York, NY, USA, 1992.

[9] V. Jarošík, L. Kratochvíl, A. Honěk, and A. F. G. Dixon, “A general rule for the dependence of developmental rate on temperature in ectothermic animals," Proceedings of the Royal Society B, vol. 271, no. 4, pp. S219-S221, 2004.

[10] F. Sehnal, "Effects of cold on morphogenesis," in Insects at Low Temperature, R. E. Lee Jr. and D. L. Denlinger, Eds., pp. 149173, Chapman \& Hall, London, UK, 1991.

[11] W. U. Blanckenhorn, "Effects of temperature on growth, development and diapause in the yellow dung fly-against all the rules?" Oecologia, vol. 111, no. 3, pp. 318-324, 1997.
[12] H. T. Ratte, "Temperature and insect development," in Environmental Physiology and Biochemistry of Insects, K. H. Hoffmann, Ed., pp. 31-66, Springer, Berlin, Germany, 1985.

[13] M. A. Jalali, L. Tirry, and P. De Clercq, "Effects of food and temperature on development, fecundity and life-table parameters of Adalia bipunctata (Coleoptera: Coccinellidae)," Journal of Applied Entomology, vol. 133, no. 8, pp. 615-625, 2009.

[14] M. R. Foerster and L. A. Foerster, "Effects of temperature on the immature development and emergence of five species of Trichogramma," BioControl, vol. 54, no. 3, pp. 445-450, 2009.

[15] D. W. Hagstrum and W. R. Hagstrum, "A simple device for producing fluctuating temperatures, with an evaluation of the ecological significance of fluctuating temperatures," Annals of the Entomological Society of America, vol. 63, no. 5, pp. 13851389, 1970.

[16] J. A. Davis, E. B. Radcliffe, and D. W. Ragsdale, "Effects of high and fluctuating temperatures on Myzus persicae (Hemiptera: Aphididae)," Environmental Entomology, vol. 35, no. 6, pp. 1461-1468, 2006.

[17] G. K. Mironidis and M. Savopoulou-Soultani, "Development, survivorship, and reproduction of Helicoverpa armigera (Lepidoptera: Noctuidae) under constant and alternating temperatures," Environmental Entomology, vol. 37, no. 1, pp. 16-28, 2008.

[18] D. M. Unwin and S. A. Corbet, Insects, Plants and Microclimate. Naturalists' Handbook, Richmond Publishing, Slough, UK, 1991.

[19] A. G. Richards and S. Suanraksa, "Energy expenditure during embryonic development under constant versus variable temperatures Oncopeltus fasciatus (Dallas)," Entomologia Experimentalis et Applicata, vol. 5, no. 3, pp. 167-178, 1962.

[20] T. Meiners and E. Obermaier, "Hide and seek on two spatial scales: plant structure differentially influences herbivore oviposition and host-finding of egg parasitoids," Basic and Applied Ecology, vol. 5, pp. 87-94, 2004.

[21] T. Meiners, B. Randlkofer, and E. Obermaier, "Oviposition at low temperatures-late season negatively affects the leaf beetle Galeruca tanaceti (Coleoptera: Galerucinae) but not its specialised egg parasitoid Oomyzus galerucivorus (Hymenoptera: Eulophidae)," European Journal of Entomology, vol. 103, no. 4, pp. 765-770, 2006.

[22] T. Ikemoto and K. Takai, "A new linearized formula for the law of total effective temperature and the evaluation of line-fitting methods with both variables subject to error," Environmental Entomology, vol. 29, no. 4, pp. 671-682, 2000.

[23] A. Campell, B. D. Frazer, N. Gilbert, A. T. Gutierrez, and M. Mackbauer, "Temperature requirements of some aphids and their parasites," Journal of Applied Ecology, vol. 11, pp. 431438, 1974.

[24] J. F. Briere, P. Pracros, A. Y. Le Roux, and J. S. Pierre, "A novel rate model of temperature-dependent development for arthropods," Environmental Entomology, vol. 28, no. 1, pp. 2229, 1999.

[25] K. P. Pruess, "Day-degree methods for pest management," Environmental Entomology, vol. 12, pp. 613-619, 1983.

[26] D. A. Herms, "Using degree-days and plant phenology to predict pest activity," in IPM (Integrated Pest Management) of Midwest Landscapes, V. Krischik and J. Davidson, Eds., pp. 4959, University of Minnesota, Minnesota, Minn, USA, 2004.

[27] P. Xu, Y. L. Zheng, X. Z. Lv, S. T. Yao, and X. X. Chen, "Biological characteristics of cionus latefasciatus (Coleoptera: Curculionidae) and effects of temperature on its growth and development," Journal of Economic Entomology, vol. 102, no. 3, pp. 1039-1043, 2009. 
[28] K. M. Clancy and P. W. Price, "Rapid herbivore growth enhances enemy attack: sublethal plant defenses remain a paradox," Ecology, vol. 68, no. 3, pp. 733-737, 1987.

[29] W. D. Brown, "Size-biased mating in both sexes of the blackhorned tree cricket, Oecanthus nigricornis Walker (Orthoptera: Gryllidae: Oecanthinae)," Journal of Insect Behavior, vol. 21, no. 3, pp. 130-142, 2008.

[30] W. D. Brown and R. Stanford, "Male mating tactics in a blister beetle (Coleoptera: Meloidae) vary with female quality," Canadian Journal of Zoology, vol. 70, no. 9, pp. 1652-1655, 1992.

[31] P. I. Ward, "The effects of size on the mating behaviour of the dung fly Sepsis cynipsea," Behavioral Ecology and Sociobiology, vol. 13, no. 1, pp. 75-80, 1983.

[32] R. Thornhill and J. Alcock, Evolution of Insect Mating Systems, Harvard University Press, Cambridge, UK, 1983.

[33] T. D. Schultz, "The utilization of patchy thermal microhabitats by the ectothermic insect predator, Cicindela sexguttata," Ecological Entomology, vol. 23, no. 4, pp. 444-450, 1998.

[34] S. A. Estay, S. Clavijo-Baquet, M. Lima, and F. Bozinovic, "Beyond average: an experimental test of temperature variability on the population dynamics of Tribolium confusum," Population Ecology, vol. 53, no. 1, pp. 53-58, 2011. 

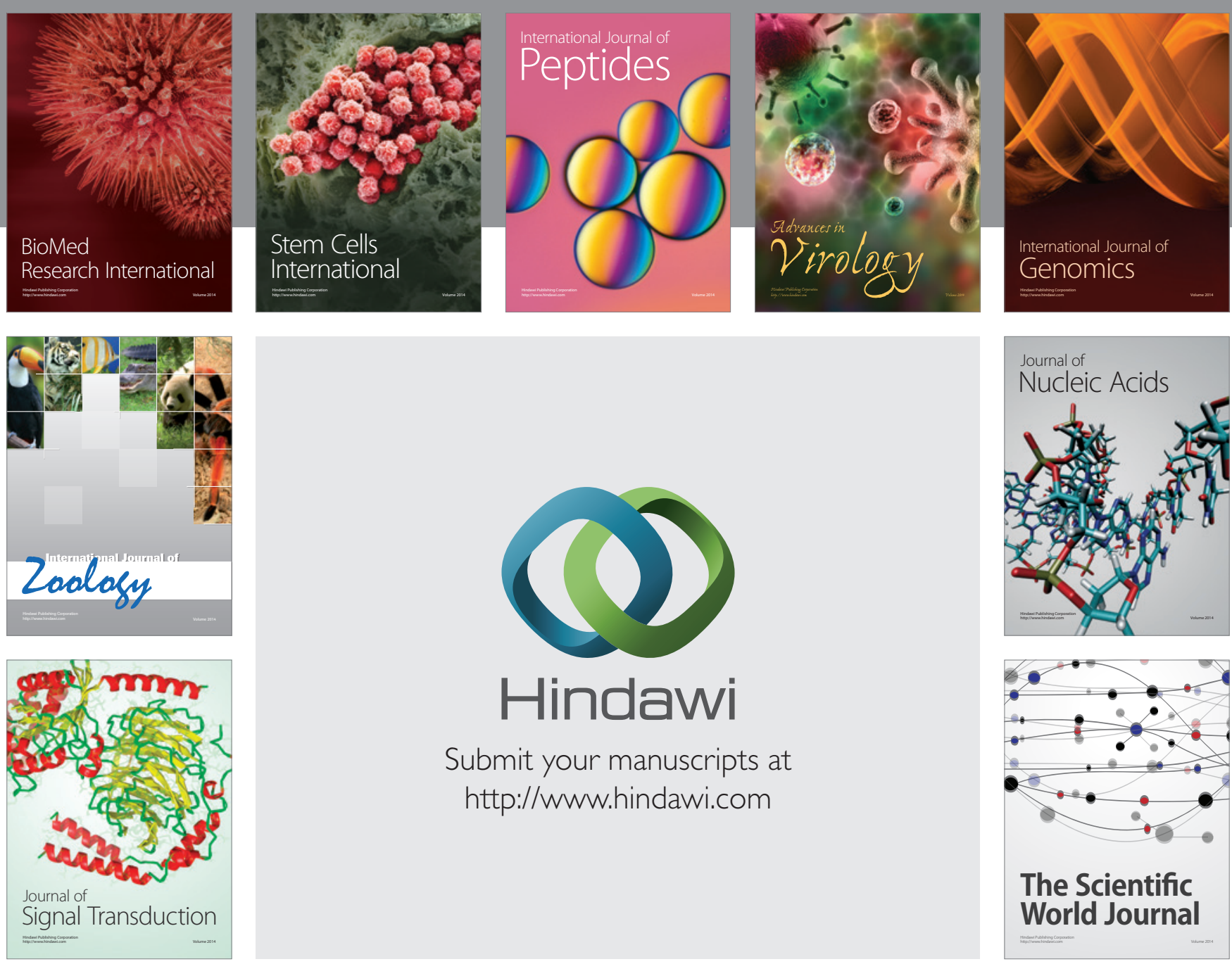

Submit your manuscripts at

http://www.hindawi.com
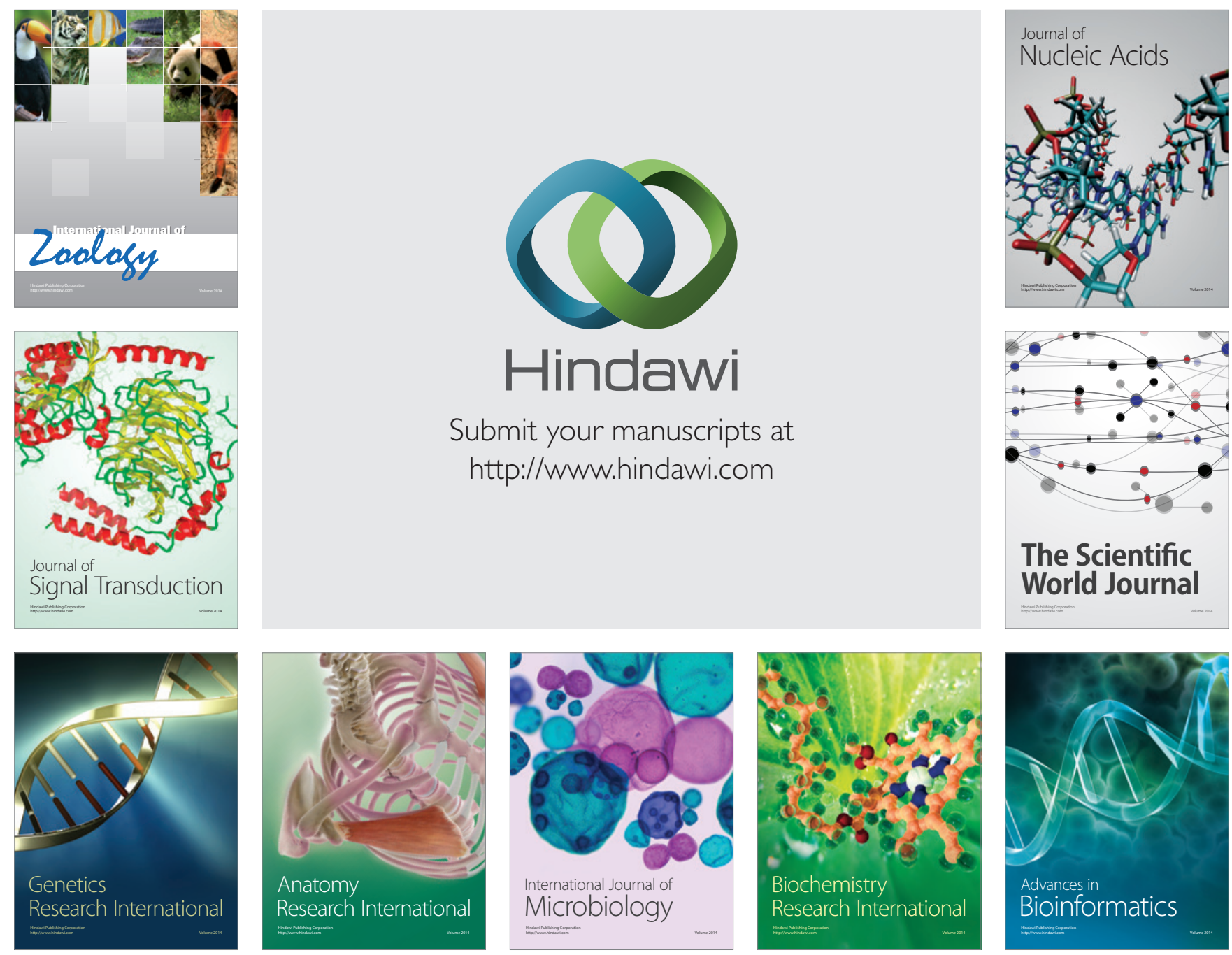

The Scientific World Journal
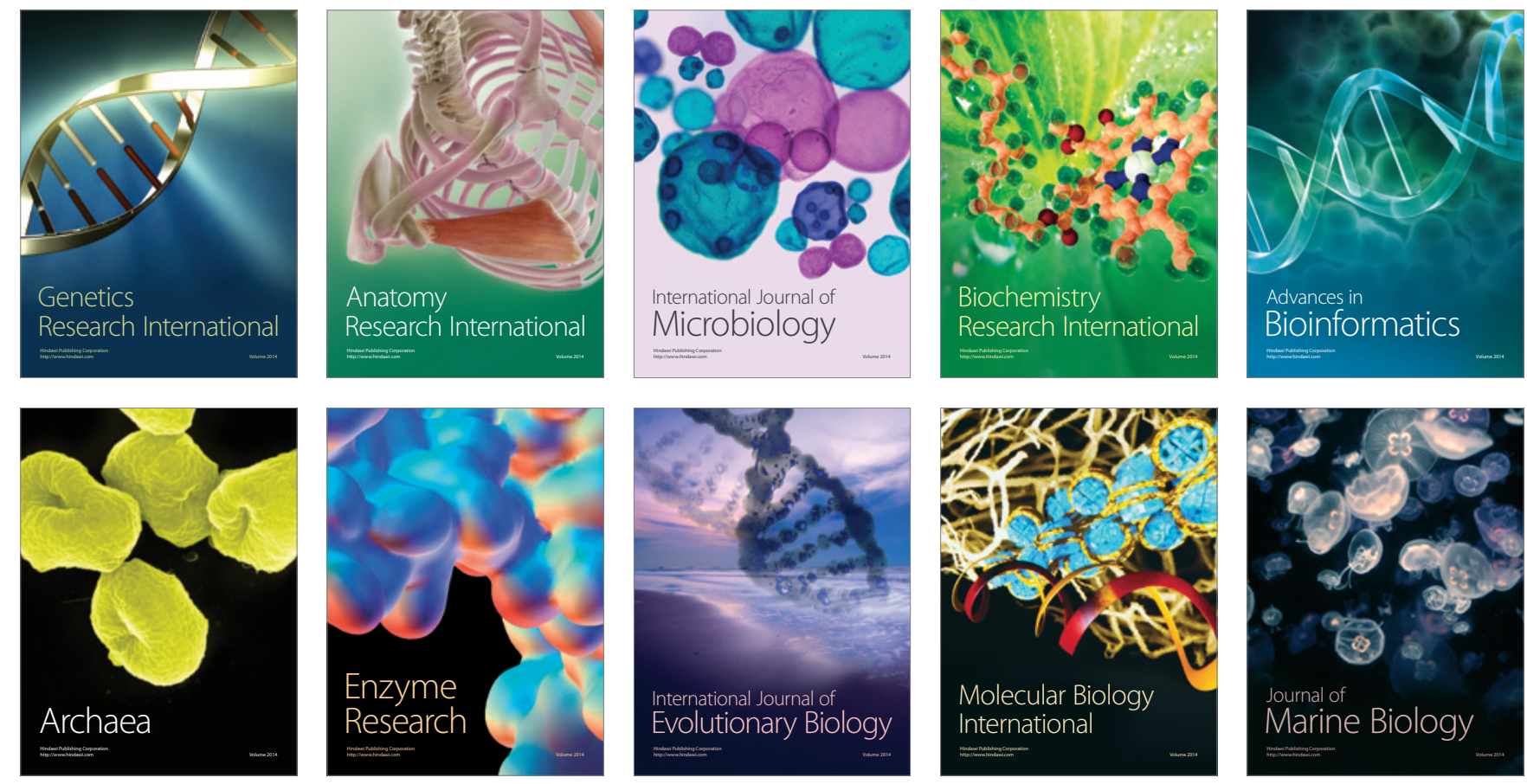